\title{
Una sugerencia para las iniciales del anónimo traductor de El contrato social de Rousseau en 1812
}

Felipe Rodríguez Morín

Sociedad Española de Estudios del Siglo XVIII

CES.XVIII, núm. 24 (2014), págs. 137-149. 


\section{RESUMEN}

Con el comienzo de la primavera de 1813, el sector más rancio del pueblo mallorquín - y el que no lo era tanto también- se vio convulsionado por la aparición de una traducción de El pacto social de Rousseau. En una remesa de 500 volúmenes, el envío remitido a Mallorca resultó poseer características particulares respecto de la edición matriz de 1.500 ejemplares que había alumbrado las prensas valencianas de José Ferrer de Orga en 1812; entre ellas la de haber permutado el título por el subtítulo de la versión original: Principios del derecho político, y la de figurar estampadas en su portada las letras «A. G-M. y S.» como indicación del traductor, sobre las cuales se han venido barajando a lo largo del tiempo distintas teorías, y para las que ahora sugerimos nosotros un candidato.

Palabras clave

Principios del derecho político, El contrato social, Antonio García Malo y Sánchez, Pedro Estala, Ignacio García Malo, Rousseau.

\section{ABSTRACT}

With the beginning of the spring of 1813, the most reactionary sector of Majorcan people -and that which wasn't so much too- was thrown into upheaval by the publication of a translation of El pacto social by Rousseau. In an edition of 500 books the consignment which was delivered to Majorca turned out to have special characteristics with respect to the former edition of 1500 copies which José Ferrer de Orga's Valencian presses had published in 1812. One of these features was that the title had been exchanged with the subtitle of the original edition: Principios del derecho político, and that letters «A. G-M. y S.» were printed on its cover as a signal of the translator. These are initials about which several theories have been considered over time and, and for which we now suggest a candidate.

KEY WORDS

Principios del derecho político, El contrato social, Antonio García Malo y Sánchez, Pedro Estala, Ignacio García Malo, Rousseau.

Recibido: 17 de mayo de 2014. Aceptado: 18 de noviembre de 2014. 
Hacia el inicio de la primavera de 1813, cuando apenas había transcurrido un mes desde la promulgación del decreto aboliendo la Inquisición (el 22 de febrero de 1813), una continuada y cada vez más enojada protesta servil alertaba al pueblo de Mallorca de los peligros de cierto libro que, impreso en Valencia en 1812 por José Ferrer de Orga, se estaba comercializando en Palma con el título de Principios del derecho político. Los testimonios, entre otros el del padre Raimundo Strauch, insistían en que había sido traducido por A. G-M. y S, en que el título era especioso, pues ocultaba una traducción de El contrato social de Rousseau, y que, dado que el libro estaba prohibido, se había distribuido clandestinamente ${ }^{1}$.

Y es que la versión de esta obra de Rousseau fue de largo el libro que mayor impacto, negativo por supuesto, causó en las abundantes huestes conservadoras de la isla; baste como evidencia de su trascendente repercusión el que Antonio Llaneras, sacerdote y diputado por Mallorca, relacionara el levantamiento popular en esa capital con la publicación de diversos papeles sediciosos, que concretaba en ese título del filósofo suizo²; o que el propio Strauch considerara

$1 \quad$ El P. Strauch afirma: «El contrato social de Rousseau lo han traducido al español A. G-M. y S. con el título: Principios del derecho político, y se ha impreso en Valencia por Josef Ferrer de Orga año 1812» (Abate BARruEL, Memorias para servir a la historia del jacobinismo [...], traducidas al castellano por F. R. S. V. [fray Raimundo Strauch Vidal], observante de la provincia de Mallorca, Palma, Felipe Guasp, 1813, tomo II, pág. 66, nota al pie). En otro lugar apuntará, además, fray Raimundo la ilegalidad en la infiltración de dicho texto en Mallorca: «los Principios del derecho político, traducidos por A. G-M. y S. introducidos clandestinamente en esta isla» (P. Strauch, «Lucio Veranio», Semanario Cristiano-Político de Mallorca, $n^{\circ}$ 38, 15 de abril de 1813, págs. 147-161). Otro impreso anónimo señala también lo siguiente: «Se supo, que el mismo Domingo había vendido varios ejemplares del pacto social de Rousseau, traducido al castellano por A. G. M. y S. bajo el especioso título Principios del derecho político» (Demostración de la verdad del manifiesto del diputado por Mallorca Don Antonio Llaneras, Palma, Brusi, 1813, pág. 14). Igualmente, un «Apologista de los Predicadores» aprovecha para realizar la siguiente denuncia cuando alude a Rousseau: «cuyo contrato social desde que se tradujo al castellano (por A. G-M. y S.) bajo el espacioso [sic] título de Principios del derecho político, mancha nuevamente el suelo español» (Ensayo de un cotejo de la carta circular que ha pasado el muy Ilustre Señor Vicario General, gobernador de este obispado, Palma, Felipe Guasp, 1813, pág. 14).

2 El Procurador General de la Nación y del Rey, de 31 de mayo de 1813, nº 243, «Artículo comunicado», firmado por A. L. Y. A. [Antonio Llaneras y Abrán]: «Es indudable que en Mallorca ha habido algún levantamiento popular, a causa del abuso de imprimir y publicar papeles denigrativos de la religión y buenas costumbres, principalmente por el escándalo de haberse publicado, traducido del francés al castellano el pacto social de Rousseau, bajo el título especioso de Principios del derecho político». 
el texto bandera de una conspiración contra el trono y el altar y crispara aún más la atmósfera política con el famoso pregón cuaresmal del 25 de marzo de 1813, previo a los alborotos del día 20 de abril, que propiciaría finalmente el ingreso del fraile en la cárcel. Este lo recuerda así el año siguiente:

Sabes que para esta prisión se me atribuyeron proposiciones, que no oíste, alguna de las cuales podía muy bien haberla proferido, pues con el Pacto social de Rousseau, que por vía reservada había llegado a mis manos el 21 del mismo marzo, comprado en casa de Miguel Domingo, tenía más que suficientes motivos para decir: que en esta ciudad había una conspiración contra el altar y el trono. No lo dije, cuando podía decirlo, porque era la verdad ${ }^{3}$.

Además de ser la más antigua fecha de que tenemos conocimiento de la circulación de esta edición en la isla, Strauch especifica que adquirió el volumen en la librería de Miguel Domingo, uno de sus grandes enemigos ideológicos ${ }^{4}$. Dicha referencia al local de Domingo quizá no resultara del todo inocente o casual en esas fechas de finales de marzo de 1814, en las que la vuelta al absolutismo parecía cosa hecha. Es más, tal denuncia fácilmente podía operar como incitación a la represalia contra el mencionado negocio; como de hecho sucedió pocas semanas después, cuando una masa de gente pretendió prender fuego a la industria del mencionado librero ${ }^{5}$. Posteriormente, en el mes de junio, cuando la victoria absolutista había sido de sobra celebrada, todavía localizamos una referencia más a la faceta «republicana y laicista» del tratado de Rousseau, que había circulado «con el piadoso fin de hacer odiosa la religión católica apostólica romana y la dignidad real $»^{6}$.

3 «Alocución» de fray Raimundo Strauch al pueblo de Mallorca, en el Semanario Cristiano-Político de Mallorca de 31 de marzo de 1814.

4 En otra ocasión oiremos a Strauch decir: «de la imprenta de Miguel Domingo salía la Aurora, y de su librería el Pacto social de Rousseau y otras alimañas» (Raimundo Strauch, Carta del P. D. Fulgencio Palet C. R. al R. P. Fr.- franciscano, y notas de este que sirven de contestación a aquella, Palma, Imprenta de Felipe Guasp, 1814, pág. 11, nota 17). Tal y como se encarga de recordar Strauch, Miguel Domingo era asimismo el editor e impresor de la Aurora Patriótica Mallorquina, verdadero azote de las posturas más reaccionarias. Por otra parte, entre las «alimañas» alumbradas por el valenciano, habría que contabilizar también otras obras del propio Rousseau, pues según refiere García Marín: «La complicidad de liberales y de Rousseau (junto con las reales afinidades que pudieran darse o no darse) se fundamentan en la expedición, aprovechando un clima ejecutivo favorable, por parte de Miguel Domingo (impresor) de casi todo el corpus rousseauniano» (Jesús García Marín, «Rousseau y el "rousseanísme” en Mallorca: reinterpretación de Un hiver à Majorque. De D’Alembert a Quadrado (1800-1840)», Taula, 1 (1982), págs. 15-20, pág. 16).

5 Vid. Miguel Ferrer Flórez, Política y represión en Mallorca (1800-1840). Sociedades secretas y liberalismo, Palma, Imprenta Politécnica, 2005, pág. 161. Ferrer Flórez recoge aquí un informe del alcalde José Desbrull sobre el intento de asalto a la oficina de Miguel Domingo.

6 Semanario Cristiano-Político, no 99 (9 de junio de 1814). 
Esta edición de 1812, que no ha de confundirse con la de 1814 — cuestión que interesa dejar bien clara ${ }^{7}$-, impresa en la misma ciudad y taller, presenta como enigma principal, en la tirada que arribó a Mallorca, la identidad de la persona enmascarada tras las iniciales «A. G-M. S.». Carola Reig apunta hacia una labor plural, e infiere que las letras corresponden a cada uno de los apellidos de sus participantes: «Las iniciales indican a Antillón, García-Malo y Salvá, el que refundió casi por completo la traducción que desde Mallorca le había mandado su amigo don Isidoro de Antillón ${ }^{8} »$.

Esta idea de una autoría colectiva fue sustentada desde la misma aparición del libro9. En El Procurador General de la Nación y del Rey Antonio Llaneras afirmaba que había sido traducido «por ciertos sujetos, amantes propagadores de la nueva, luminosa, pero negra e impía ilustración, bien conocidos por las letras iniciales de sus respectivos nombres, pintados en la misma traducción impresa». Unos meses más tarde, en el Semanario Cristiano se insiste en este aspecto: «traducido al castellano por unos señoritos no serviles cuyas iniciales son bien conocidas, bajo el especioso título de principios del derecho político». El propio Strauch había advertido: «Este escrito contra los tronos lo han traducido y hecho imprimir unos sujetos ya bien conocidos por su odio al altar ${ }^{10} »$.

Pese a que unos y otros supongan una autoría compartida y se insinúe que era fácilmente reconocible la identidad de los responsables, hasta donde se nos alcanza ningún coetáneo la consignó por escrito, lo que puede resultar indicativo de que quizá no existía al respecto tanta seguridad como se pretendía aparentar.

De hecho, hubo sus dimes y diretes sobre este particular. Llaneras alude a Antillón y a Salvá, aunque sin mencionarlos, el 31 de mayo de 1813, refiriendo que los traductores son «tres sujetos muy unidos en sentimientos científicos y prácticos, y que dos de ellos tuvieron que huir de aquella isla por no perder su pellejo»; a este tenor, ha de recordarse que Antillón se había ausentado de Palma de Mallorca para tomar posesión en Cádiz como diputado en Cortes el 23 de mayo de 1813. Por su parte, el Semanario Cristiano insertó en octubre

7 A tales efectos, conviene precisar que de este texto existe un ejemplar en la Biblioteca Nacional de Madrid, con la signatura 4/19894 y código de barras 1002227199, que luce el siguiente rótulo en portada: «Principios del derecho político, traducido nuevamente del francés al castellano por A. G-M. y S., en Valencia, por José Ferrer de Orga. Año 1812».

8 Carola Reig Salvá, Vicente Salvá, un valenciano de prestigio internacional, Valencia, Instituto de Literatura y Estudios Filológicos, 1972, pág. 312.

9 Quizá coadyuvara a ello esa «y» minúscula que enlazaba la «G» con la «S» final.

10 El Procurador General de la Nación y del Rey no 269 (26 de junio de 1813); Semanario Cristiano $\mathrm{n}^{\circ} 60$ (9 de setiembre de 1813), nota 54; Abate BARRUEL, Memorias para servir a la historia del jacobinismo, op. cit., t. II, pág. 66, nota. 
un artículo del Tribuno del Pueblo Español que desmentía la anterior aseveración de Llaneras: «la persona, a quien particularmente se ha propuesto zaherir el articulista del Procurador, ni ha tenido la menor parte en la traducción de los Principios del derecho político de Rousseau, ni ha salido de allí a escondidas, sino después de haber anunciado su viaje con anticipación». Y aprovecha la ocasión el mentado Semanario Cristiano —al paso de denunciar que algún ejemplar del citado libro del ginebrino fue trasladado desde Mallorca a Cádizpara hacerse la siguiente pregunta: « $\gtreqless \mathrm{Y}$ el portador o comisionado o como se llame sabría descifrar el enigma misterioso de aquellas iniciales de su traductor o traductores, A. G-M. y S. ¿Conocería estos embosado? [sic] ¿Tendría conexión o amistad con ellos ${ }^{11}{ }$.

Si había dudas sobre la autoría de Antillón, también cabe cuestionar la de Ignacio García Malo, puesto que en su necrológica, publicada en la Aurora Patriótica Mallorquina de 1 de julio de 1812, atribuida a Antillón, se dejaba constancia que su último trabajo literario había sido una traducción, sí, pero de La política natural, en 1811. Por lo tanto, si quedaban excluidas las iniciales «A» de Antillón y «G-M» de García Malo, también convendría cuestionar la atribución de la «S» final a Vicente Salvá. Además, no parece que para trasladar una obra del francés al castellano hicieran falta tantas personas.

Recientemente, Ramírez Aledón, tras examinar estos pormenores de la autoría múltiple propuesta por Carola Reig, así como otros diversos argumentos, entre ellos la declaración de los libreros Mallén y Salvá ante el Santo Oficio, concluye adjudicando la traducción a Pedro Estala, y sugiere que la aparición del acrónimo apunta a una maniobra de distracción ante la censura, porque «los tiempos habían cambiado». Aserto este último que proviene del hecho de que Ramírez Aledón supone que esta versión de la obra de Rousseau tuvo lugar a fines de 1813, o en $1814^{12}$.

Dicha hipótesis dejaba sin resolver de forma convincente, a nuestro entender, el motivo de las letras «A. G-M. y S.» estampadas en la portada del libro; pues, contrariamente a la opinión vertida por Ramírez Aledón, no las sospechamos nosotros artificio de una treta editorial concebida para despistar a las autoridades, especialmente en aquel primer trimestre de 1813, en el que,

11 A. L. Y. A., El Procurador General de la Nación y del Rey, $\mathrm{n}^{\circ} 243$ (31 de mayo de 1813, cit.); Semanario Cristiano, $\mathrm{n}^{\circ} 64$ (7 de octubre de 1813), pág. 541.

12 Germán Ramírez Aledón, «Rousseau en la revolución liberal española: la edición en España de $E l$ contrato social (1812)», Cuadernos de Ilustración y Romanticismo, nº 18 (2012), págs. 211-230. «En nuestra opinión, Estala tradujo El Contrato social por encargo o sugerencia del mariscal Suchet o del jefe de la policía de Valencia, Agustín Quinto, y se dejó guiar y aconsejar por Marchena, pues el sevillano también estaba entonces en Valencia», pág. 227. Cita anterior en pág. 219 
conforme a los numerosos testimonios que hemos plasmado, había circulado por Palma de Mallorca ${ }^{13}$; puesto que eran fechas aquellas en las que se acababa de abolir la Inquisición, y donde la sensación reinante era la de que se avanzaba de forma inexorable hacia una mayor tolerancia en lo tocante a la circulación de papeles impresos.

Prosiguiendo con esta intención de enmarcar los acontecimientos en su contexto, y centrándonos ahora en las ediciones de la obra origen de los interrogantes, debemos referirnos a la que suponemos que fue la primera de ellas, esto es a la valenciana de 1812, alumbrada en la imprenta de José Ferrer de Orga, con la siguiente rúbrica en su portada: «El contrato social, o principios del derecho político: por Juan Santiago Rousseau, ciudadano de ginebra». La siguiente hoja decía: «Esta nueva traducción del Contrato social es propiedad del editor».

Probablemente unos meses más tarde, pues no tenemos noticia de ella hasta marzo de 1813, se publicó una tirada nueva, gemela de la anterior en todo, pero con algún pequeño detalle diferenciador, exclusivo solo de sus hojas inaugurales y de la última. Al igual que su predecesora, llevaba en su primera página, como datos de edición, el año de 1812, el nombre del impresor, José Ferrer de Orga, y la ciudad de Valencia; pero en cambio aparecía modificado su título, ya que ascendía a tal categoría el subtítulo anterior: «Principios del derecho político», quedando eliminado también el nombre del autor y la localidad suiza de procedencia, a la par que se incluía la famosa serie de letras como perteneciente al traductor o traductores: «traducidos nuevamente del francés al castellano por A. G-M. y S.», con el añadido, asimismo, del siguiente verso y fuente de procedencia: «foederis aequas Dicamus leges. Aeneid. XI».

Por lo que respecta a la edición de 1814, ha de reseñarse que conservaba una portada similar a la última de 1812, con la misma frase latina, impresor y ciudad, aunque se ve exenta ahora de las famosas iniciales, así como del término «nuevamente» para calificar la traslación: «Principios del derecho político, traducidos del francés al castellano».

Con todo, y a pesar de algunas ligeras variantes, el principal elemento diferenciador de esta reedición de 1814 es el que nos da a conocer una «Nota del traductor» al pie de la penúltima página: «He suprimido todo el capítulo VIII que habla de la religión civil, por parecerme opuesta su doctrina al art. 12 de nuestra Constitución política» (pág. 317).

13 En muy elevado número, por cierto, ni más ni menos que 500, según reconocen sus propios enemigos: «corren muchos ejemplares del contrato social de Rousseau bajo el título de: Principios del derecho político, traducidos nuevamente del francés al castellano por A. G-M. y S. [...]. De este maldito libro se han introducido, según noticias, quinientos ejemplares» (Semanario Cristiano-Político, de 25 de abril de 1813, nº 40, bajo el epígrafe: «Libros malos que circulan por esta ciudad»). 
Varios años después, restablecido el absolutismo en España, la Inquisición se propuso indagar seriamente acerca de la responsabilidad de la traducción y de los individuos que habían tenido parte en ella. Como se puede suponer, la Suprema inició su investigación por el dato que le resultaba conocido, y por eso el 7 de julio de 1819 llamó a testificar al titular del pie de imprenta, José Ferrer de Orga, quien respondió que habían salido a la luz en su oficina «como mil y quinientos ejemplares de esta obra por orden de Mallén Salvá y Compañía» ${ }^{14}$. La pista a seguir estaba clara, y el Santo Oficio procedió a interrogar a los dos referidos libreros.

Unos cuantos días después, el 31 de julio, los dos comerciantes fueron preguntados, desde luego, por el número de ediciones de que gozó el tratado rousseauniano, «y respondieron conformes que dos, variando en el tiempo. El primero dice que la $1^{\mathrm{a}}$ íntegra fue el año 1811, y la $2^{\mathrm{a}}$, sin el tratado de Religión, en el 14. Salvá dice que la $1^{\text {a }}$ fue el año de 12 y la $2^{\mathrm{a}}$ en fin de 13 , y principios del $14 »$.

No hay alusión ninguna, como se ve, a la tirada que conjeturamos intermedia entre la primera de 1812 y la de 1814. Tampoco nadie efectúa mención alguna acerca de las célebres iniciales: los inquisidores porque desconocen la existencia de esa impresión, y los interpelados porque evitan, previsiblemente, añadir información adicional que pudiera implicar o complicar a alguien más en el asunto; si acaso sí que se permiten la sempiterna licencia de derivar la responsabilidad del problema hacia alguien que ya estaba muerto, puesto que cuando se les interrogó por orden de quién se habían hecho las ediciones, ambos contestaron «acordes» que se habían llevado a cabo por encargo de «D. Pedro Estala», y que la razón de haberse suprimido el capítulo relativo a la religión fue consecuencia de que, al hallarse aquel en Francia al momento de imprimirse la segunda edición, y previa consulta con «don Isidoro Antillón», este les había aconsejado eliminarlo ${ }^{15}$.

Un embuste, del mayor interés para desacreditar la declaración de los libreros, lo constituye el referido a la modificación del título de la obra. Al res-

14 Archivo Histórico Nacional, Inquisición, 3732-316, f. 3v.

15 AHN, Inquisición, 3732-316, f. 11v. Antillón había fallecido en 1814 y Estala en 1815. Ramírez Aledón afirma al efecto: «Varias mentiras de estrategia defensiva contiene esta declaración: es difícil creer que Mallén ignorase lo que dice y atribuir a Estala la traducción era trasladar la prueba del delito a un fallecido» (op. cit., pág. 222. Vid. AHN, Inquisición, 3723-316, f. 4r.). En alguna ocasión, incluso, la contradicción entre lo que atestiguan y lo que figura publicado se hace en extremo evidente; así por ejemplo cuando los dos responden que la nota que se hallaba al final de la segunda edición era «del editor don Pedro Estala, como de ella misma constaba» (AHN, Inquisición, 3732-316, f. 12r.), resultando la realidad que lo que se lee allí es «Nota del traductor», según ya antes indicamos. El mismo Ramírez Aledón duda también de la sinceridad de los libreros, y así lo hace observar cuando, en su citado artículo, emplea expresiones del siguiente tipo: «varias mentiras de estrategia defensiva» (pág. 222); «esta última aseveración no parece ser muy fiable» (pág. $223)$, etc. 
pecto, los interrogadores habían inquirido por qué en la edición de 1814 habían cambiado aquel, suprimido el nombre del autor y el tratado de religión si los promotores de la iniciativa estaban convencidos, tal y como afirmaban, de que el libro no se hallaba incluido en el Índice expurgatorio. Mallén, en su línea, contestó que como él no había corrido con la impresión, sino que lo había hecho su socio Salvá, desconocía los motivos. Este, por su parte, atribuyó esta novedad a un argumento que sin duda traía bien aprendido, y que venía a decir que Estala había alterado el título y omitido el nombre de Rousseau de su traducción porque, al erradicar el apartado concerniente a la religión, «le pareció impropio titularla Contrato social, con el que se calificaba la obra entera del autor ${ }^{16} »$.

Pero tal explicación sabemos que de ningún modo podía ser cierta, puesto que el título ya había sido alterado y la referencia al nombre del autor eliminada en la versión que, con las célebres iniciales, había circulado por Palma de Mallorca desde, al menos, el mes de marzo de 1813, la cual mantenía, sin embargo, el capítulo VIII: «De la religión civil»; prueba palmaria que la alteración de la portada no dimanaba en absoluto de la supresión del referido apartado sobre la religión.

En cambio, los reaccionarios mallorquines sí que poseían a la altura de 1813 y 1814 una explicación convincente para el caso, puesto que con la aplicación del adjetivo «especioso», con el que casi siempre calificaban al libro, daban a entender que este se valía de esas argucias de modificar el título y de suprimir la identidad del filósofo suizo para penetrar, como de tapadillo, en hogares en los cuales la sola mención de El pacto social o del nombre de Rousseau podían provocar un insalvable rechazo ${ }^{17}$.

Por su parte, Mallén y, especialmente, Salvá habían ya previamente incurrido en otra contradicción ante la autoridad inquisitorial, que si bien pareció pasar inadvertida, para nosotros resulta altamente significativa. Estribaba esta en que, habiendo asegurado anteriormente ambos que habían consultado con Antillón (porque Estala se hallaba en Francia) la posibilidad de imprimirse, o no, el capítulo sobre la religión, tras ser reconvenidos en ese acto por el inquisidor para que contestasen por qué se había suprimido si el traductor (según la versión de ellos, Estala) les había asegurado que el libro era conforme a las ideas que emanaban del Gobierno, Mallén respondió ahora que lo ignoraba «porque corrió su socio con dicha impresión». Por su parte, la respuesta de Salvá llama aún más la atención, ya que, tras corroborar las palabras de Mallén

16 AHN, Inquisición, 3732-316, f. 13r. y v.

17 Es la tesis de, por ejemplo, fray Raimundo Strauch: «¿qué intentabais vosotros introduciendo traducido al castellano y con el disfraz de principios del derecho público el pacto social de Rousseau?» (Semanario Cristiano-Político de 31 de marzo de 1814, nº 89). 
relativas a que este desconocía el asunto, apuntó a que fue el mismo traductor quien accedió a la eliminación del cuestionado epígrafe, una vez que había sido advertido por el propio Salvá «de las dificultades que había ${ }^{18}$ ».

Es decir, si bien inicialmente Mallén y Salvá alegaron que la exclusión del capítulo fue recomendada por Antillón, porque Estala se hallaba en Francia, ahora Mallén dice desconocer el motivo de esa poda y Salvá informa de la aquiescencia en ella de Estala.

Una causa, nada descabellada en nuestra opinión, que podría explicar dicha incoherencia residiría en el hecho de que cuando se les pregunta por la identidad del traductor saben que tienen que manifestar, de forma obligada y de antemano convenida para protegerlo, el nombre de Estala; pero una vez desembarazados de ese peso, y con el transcurso de la conversación, la figura del traductor que acude a su mente no sería, sin embargo, la del escolapio manchego, sino la que realmente guardaban en su recuerdo ${ }^{19}$.

Por otra parte, a pesar de lo que llevamos argumentado, el descarte de Estala como autor de la traducción no constituye estorbo ninguno para suponer que hubiera podido jugar algún papel, incluso de cierta relevancia, en la ejecución de tal iniciativa. Es más, el hecho mismo de que Mallén y Salvá sacaran a relucir su nombre ante el Santo Oficio ya se erige en sustancial indicio a favor de esa teoría.

Confluyendo con la pista de Estala, quizá contemos, siquiera como mera hipótesis, con un candidato identificable con las siglas, puesto que sus iniciales coinciden punto por punto con las del supuesto traductor, y que poseyó, además, los medios, la ocasión y los conocimientos necesarios para llevar a cabo la dichosa versión hispana de la obra de Rousseau. Nos estamos refiriendo concretamente a Antonio García-Malo y Sánchez, hermano mayor de Ignacio, y arcipreste desde el 20 de mayo de 1790 en su pueblo de Castillo de Garcimuñoz, provincia y obispado de Cuenca ${ }^{20}$.

En dicha localidad, el hijo de Pablo García Malo de la Fuente (alcalde de su pueblo por el estamento noble) y de Ignacia Sánchez del Prior, que recibió en el bautismo los nombres de Antonio José Manuel, vio por primera vez la luz el 16 de junio de 1758, y en ese mismo lugar murió el 7 de diciembre de

18 AHN, Inquisición, 3732-316, f. 12r.

19 Persona esta con la que, tal vez, tuvieron que volver a entrar en contacto unos meses después, ya que, retornado el liberalismo a España, la misma traducción fue alumbrada de nuevo en 1820.

20 En un anterior trabajo barajamos ya la hipótesis de su autoría, que pretendemos examinar ahora con algo más de detenimiento (vid. Felipe Rodríguez Morín, «La traducción española de La política natural: una forma natural de traducir la política en la España de 1811", Cuadernos de Estudios del Siglo XVIII, n. ${ }^{\circ}$ 22 (2012), págs. 61-92, págs. 67-68). 
$1834^{21}$. Por otro lado, y a excepción de cierta carta destinada a su hermano Ignacio $^{22}$, el escaso conocimiento que de su vida tenemos se nutre casi exclusivamente de documentos notariales y de actuaciones burocráticas o administrativas.

Y es en este ámbito donde nos topamos — con motivo de las diligencias practicadas para la designación de su hermano Ignacio García Malo como caballero de la Orden de Carlos III — con las siguientes palabras de Antonio: «Don Antonio García Malo y Sánchez [...], apoderado de mi hermano entero Don Ignacio García Malo y Sánchez ${ }^{23}$ ». Gracias a este testimonio podemos comprobar que Antonio utilizaba el «García Malo» como primer apellido, y la conjunción «y» como nexo entre este y el segundo. De ese mismo modo, además, concluía firmando al pie de su declaración.

Respecto de la ciudad en la que se publicó la versión española de Rousseau, ha de decirse que monseñor José García Malo, camarero secreto del papa, prelado doméstico de Su Santidad, tío de Antonio y de Ignacio, ostentaba la dignidad de sacrista de la Iglesia de Valencia, si bien, por residir en Roma, figuraba como ausente en la Guía del Estado Eclesiástico Seglar y Regular, de España en particular, y de toda la Iglesia Católica en general, al menos en lo relativo a los años que van de 1807 a 1814. Por tal causa, se había ocupado don Ignacio durante mucho tiempo de la administración de sus bienes, como apoderado suyo, hasta que precisamente en 1812, sintiendo ya cercana su muerte, le pasó el relevo a su hermano Antonio ${ }^{24}$.

Llegamos de este modo con Antonio García Malo a Valencia y, por ende, a Pedro Estala; pero para poder establecer una conexión entre ellos debemos recurrir de nuevo a la intermediación de Ignacio García Malo, de quien sabemos que pertenecía al mismo círculo de amistades que el escolapio por lo menos desde 1788 o principios de $1789^{25}$. Aunque carecemos de constancia fehaciente de que la relación entre Ignacio e Estala se hubiera hecho extensiva también a Antonio, no resulta difícil pensar que cada uno de ellos seguramente poseía

${ }^{21}$ Archivo Diocesano de Cuenca, Libro de Bautismos, de 1739 a 1761, Sección Parroquias, ${ }^{\circ}$ 1667, f. 232v., y Libros Parroquiales, no 1683, f. 131v., respectivamente.

${ }_{22}$ Archivo General de Palacio, Libros parroquiales, caja 4812.

23 AHN, Estado, Orden de Carlos III, expediente 1119, folio 73v.

24 Véase el testamento de Ignacio García Malo, otorgado el 24 de mayo de 1812, ante el escribano Cayetano González (Archivo del Reino de Mallorca, Protocolos, G-832, h. s. n.).

25 Tal se desprende de una carta de Juan Clímaco de Salazar al propio Ignacio García Malo, conservada, junto con otras 16 más, en la Real Academia Española: Legado Rodríguez Moñino, RM-CAJA 73-26. La relación entre ambos ilustrados persistió en el tiempo, pues en 1792 Estala e Ignacio García Malo, como ya puso de manifiesto Aguilar Piñal (La prensa española en el siglo XVIII. Diarios, revistas y pronósticos, Madrid, CSIC, 1978, pág. 39), pretendieron sacar juntos a la luz un periódico: el Diario Enciclopédico, aunque se opuso a ello el censor (AHN, Consejos, 11279-75, s/n). 
noticia del otro, aunque no fuera más que para poder recurrir a él en caso de necesidad, especialmente en aquellas singulares condiciones en que se hallaba la Península, dominada por los franceses.

Precisamente a cuenta del descalabro josefino en la batalla de los Arapiles podemos establecer un hipotético punto de encuentro entre ambos a finales de agosto de 1812, puesto que la Corte, y con ella Estala, se vio abocada a abandonar Madrid rumbo a Valencia. En esa ruta, poco antes de mitad de camino, constituye paso obligado la localidad conquense de Castillo de Garcimuñoz, parroquia en la que, recordemos, Antonio García Malo ejercía sus funciones sacerdotales.

Otro lugar de confluencia, más perdurable sin duda, en aquellos meses finales de 1812, pudo resultar, desde luego, la misma ciudad de Valencia, para el «afrancesado» D. Pedro estación de retiro forzosa, y para Antonio García Malo de negocio sobrevenido con el traspaso por parte de su hermano - conforme ya hemos señalado- de los poderes para administrar los bienes de su tío, el canónigo residente en Roma. Y sea el asunto como fuere, la cuestión es que parece prudente considerar que, para el caso de querer publicar una traducción, no debían de existir muchos individuos con más experiencia que Estala a los que solicitar asesoramiento o consejo.

Materia distinta sería explicar la razón de por qué solo la remesa de libros enviada a Mallorca llevaba impresa en portada las iniciales del presunto autor de la versión. A dicha circunstancia posiblemente no hubo de ser ajena la condición de presbítero en ejercicio de Antonio, pues no resultaría muy apropiado que un hombre de iglesia, pastor de las almas en su pueblo conquense, pudiera verse envuelto en un escándalo que a priori, ya antes de la aparición del título, se presagiaba que había de provocar el libro, y que posteriormente se encargó de ratificar la realidad. Tal vez por eso saliera totalmente anónima la primera tirada, sin pista alguna que sugiriera una filiación a la que algunos de sus vecinos o conocidos sin mayor dificultad pudieran asociar las cinco letras.

En cambio, en la segunda impresión, destinada según creemos a la isla mediterránea, lejos por tanto del círculo en el que habitualmente se movía Antonio, le resultaría a este muy a modo el estampar las siglas, aunque no fuera más que en homenaje a su hermano, miembro del bando liberal, pocos meses antes fallecido en Palma, cuyo aprecio y afecto hacia él por parte de sus camaradas, que sin duda conocían la identidad del dragomán, resultaba garantía suficiente para no desvelar el secreto de su nombre ${ }^{26}$. Por otra parte, esta segunda tirada posi-

${ }^{26}$ Entre los grandes amigos de Ignacio García Malo en Mallorca debemos destacar al impresor y librero Miguel Domingo, cuyo establecimiento palmesano se apresuró en distribuir, según hemos señalado, la citada versión de la obra de Rousseau. 
blemente fuera alumbrada inmediatamente después de la supresión del Santo Oficio, inoperante en Valencia durante el dominio francés, pero activa todavía en la España no ocupada hasta febrero de 1813; y quizá por ello pudo permitirse el lujo, siquiera modesto, de signar de alguna forma su trabajo el autor de la traslación, brindando, a la par, un guiño a los liberales mallorquines.

Si Antonio García-Malo y Sánchez hubiera tenido parte en la traducción, cuestión que hemos suscitado aquí a título de simple sugerencia, habría que concluir recalcando la circunstancia de que un cura de pueblo fue capaz de alzar en armas verbales a todo un regimiento, especialmente nutrido de reaccionarios, que durante más de un año se revolvió con miedo y furia contra su traducción, considerada el mayor ataque jacobino que había sufrido la, hasta pocos meses antes, tranquila isla de Mallorca. 